\title{
Effect of Oxygen Addition in Steam Gasification of Chicken
}

\author{
Manure
}

\author{
M. S. Hussein ${ }^{1}$, K. G. Burra ${ }^{2}$, R. S. Amano ${ }^{3}$ and A. K. Gupta ${ }^{4}$ \\ Department of Mechanical Engineering \\ University of Maryland \\ College Park, MD 20742, USA
}

\begin{abstract}
The continued increase in the production scale of chicken industry have led to increased use of chicken manure as fertilizers or landfill disposal which leads to land and water pollution by eutrophication from landfills. Thus, although chicken manure is rich in ash and moisture content, thermochemical waste to energy techniques such as gasification of chicken manure makes it an efficient alternative energy source with clean waste management. The role of oxygen addition to steam gasification of chicken manure at different concentrations was examined and evolutionary behavior of the gases evolved with time were analyzed using gas chromatography. Isothermal conditions were maintained in a semi-
\end{abstract}

${ }^{1}$ Graduate Student, University of Wisconsin, Milwaukee, WI, USA

${ }^{2}$ Graduate Student, University of Maryland, College Park, MD, USA

${ }^{3}$ Professor, University of Wisconsin, Milwaukee, WI, USA

${ }^{4}$ Distinguished University Professor. Email: akgupta@ umd.edu, Phone: 301.405.5276

Keywords: Steam/oxygen gasification, chicken manure, biomass, evolved syngas analysis, renewable energy 
batch reactor at a temperature of $1173 \mathrm{~K}$ while the oxygen concentration was increased from $0 \%$ to $12 \%$ (dry basis). From the oxygen concentrations examined, the addition of oxygen decreased the reaction duration by $50 \%$ while improving the syngas characteristics and energy yield on short periods. The reduction in energy yield was limited to minimal amounts that varied from $4 \%$ to $15 \%$ with reduction directly proportional to oxygen content in the gasifying agent. Accumulative yield of carbon monoxide was maximum for oxygen concentration of $9 \%$ (dry basis) above which extra oxygen concentration caused further oxidation of the syngas components to decrease the energy content of syngas yield. The results revealed reduction in net energy requirements by decreasing the reaction time by up to $70 \%$ (for oxygen content of $12 \%$ ) with minimal reduction in energy content from syngas yield and improved carbon conversion. These results provide improved design strategies for better waste to energy technique by addition of oxygen to steam during gasification of chicken manure.

\section{Introduction}

Given the average chicken meat consumption and the average manure production per chicken, the US annual dry chicken manure production is estimated to be 12 billion pounds [1]. Some states, where the chicken production continues, are suffering with increasing environmental issues [2]. In the state of Maryland, it was found that the 
concentration of phosphorous in the soil is $60 \%$ higher than the levels required for plant growth, which has made phosphorous as a soil pollutant [2]. Chicken manure was attributed for the high phosphorus concentration in the soil. The local use of chicken manure as a fertilizer is no longer an option so that it must be transported or reformed into usable energy [3]. Gasification of chicken manure can help reduce fossil fuel consumption to help extend their availability. This waste conversion also helps in the mitigation of greenhouse gases as energy produced from wastes and biomass is nearly carbon neutral. Such an energy source has a carbon-neutral effect on greenhouse gas emissions due to their renewable output and disposal [4]. Pyrolysis and gasification of wastes is an efficient solution over direct combustion, as it can produce liquid/syngas fuels of medium to high heating value, which can be utilized with the currently available infrastructure for energy and power generation, and transportation. Thermochemical conversion methods such as gasification are industrially viable options compared to biochemical conversion methods such as anaerobic conversion due to the high reaction rates provided by gasification.

Gasification is an efficient thermochemical decomposition of solid carbonaceous material to product gases of higher heating value compared to the solid precursor in the presence of gasifying agents such as steam, air, or $\mathrm{CO}_{2}$. The major components of product gas are $\mathrm{H}_{2}, \mathrm{CO}, \mathrm{CO}_{2}, \mathrm{CH}_{4}$, and other higher hydrocarbons. Undesirable byproducts containing a mixture of heavy aromatic hydrocarbon residues, referred to as tar, are also formed which must be further pyrolyzed or reformed to enhance the syngas yield. Gasifying agent, temperature, feedstock composition and other reactor operational 
parameters affect the composition of syngas evolved from gasification. Production of homogeneous fuel (syngas as intermediate) from heterogeneous combination of sources including chicken manure, poultry litter, biomass, solid wastes, and coal makes it an attractive solution over direct combustion of these low-value heterogeneous feedstocks providing feed flexibility along with versatility. Abundant literature is available on the effects of using different catalysts, gasifiers, and favorable temperatures on biomass gasification [4-19]. Equations (1-5) show the major governing reactions (considering C to represent the biomass) that occur during gasification [20].

$$
\begin{array}{ll}
\text { Char Oxidation: } & \mathrm{C}+\mathrm{O}_{2} \Rightarrow \mathrm{CO}_{2} \\
\text { Boudouard Reaction: } & \mathrm{CO}_{2}+\mathrm{C} \rightleftharpoons 2 \mathrm{CO} \\
\text { Water-gas shift Reaction: } & \mathrm{CO}+\mathrm{H}_{2} \mathrm{O} \rightleftharpoons \mathrm{CO}_{2}+\mathrm{H}_{2} \\
\text { Water-gas Reaction: } & \mathrm{C}+\mathrm{H}_{2} \mathrm{O} \rightleftharpoons \mathrm{CO}+\mathrm{H}_{2} \\
\text { Thermal cracking: } & \mathrm{C}_{\mathrm{n}} \mathrm{H}_{\mathrm{m}} \Rightarrow \mathrm{C}+\mathrm{C}_{\mathrm{x}} \mathrm{H}_{\mathrm{y}}+\mathrm{H}_{2}
\end{array}
$$

Chicken droppings, waste beddings, waste food, and feathers from the coops form the major source from poultry litter. High nitrogen content due to proteins and amino acids, high phosphorus and ash content are characteristics of poultry litter making them low grade feedstock that are different from conventional biomass such as wood. Such differences form the motivation for investigation into the pyrolytic behavior of chicken litter [21]. One of these differences investigated from thermal gravimetric analysis (TGA) was the start of decomposition at lower temperatures compared to coal wherein maximum weight loss rate was observed at $643 \mathrm{~K}$ [22]. The TGA results on the pyrolysis of chicken litter showed three stages of weight loss, unlike woodchips pyrolysis which 
occurs in two stages because of lignocellulose content. Three stages of chicken litter decomposition observed from the TGA were decomposition of cellulose and hemicellulose with a peak at a temperature less than that of wood chips, followed by manure and lignin decomposition and the last stage of residual char devolatilization. This is unlike TGA of wood chips pyrolysis which showed only two stages [21]. Higher manure content assisted in faster decomposition of waste litter. Increase in temperature increased syngas yields, and decreased liquid and char yields [23]. $\mathrm{CO}_{2}$ yields increased due to decarboxylation of minerals carbonates in the ash at temperatures above $973 \mathrm{~K}$ until a stable value above $1273 \mathrm{~K}$ [22]. Highly viscous bio-oils produced from fast pyrolysis of chicken litter had less acidity and higher heating value compared to bio-oils from hardwood due to the decomposition of protein content in chicken litter into hydrocarbons [24].

Although the high inorganic content in chicken litter can provide fertilizing capabilities, and catalytic activity in syngas production, it causes handling difficulties due to the low fusion temperature of inorganics present since the chicken litter ash contains high amounts of $\mathrm{Ca}, \mathrm{Na}$, and $\mathrm{K}$. Such high amounts of ash content (>20\%) in chicken litter with phosphorous and potassium oxides makes it an efficient fertilizer even after gasification [25]. The gas evolution from inorganic matter in manure such as decarboxylation of carbonates and the low melting points of its constituents induces error into modeling of product gases from high-temperature gasification and pyrolysis if ash is considered inert as in conventional models [26]. 
Chicken litter gasification was demonstrated by blending with coal and found no change in the heating value of product gas [27]. Ultimate analysis showed enough oxygen presence in chicken litter to gasify its carbon contents; such method was called "autogasification" [28]. This investigation also found ineffective availability of carbon to react with oxygen due to reactions with other hydrocarbons and water gas reaction causing oxidation of $\mathrm{CO}$ evolved to form $\mathrm{CO}_{2}$. Use of catalysts in steam gasification of chicken manure in a fluidized bed at temperatures around $873 \mathrm{~K}$ produced syngas rich in $\mathrm{H}_{2}$ content and total gas yields with the addition of $\mathrm{Ni}-\mathrm{Al}_{2} \mathrm{O}_{3}$ catalyst [29]. Supercritical gasification of chicken manure was also investigated [30,31]. Abundant literature on biomass although helpful in assessing chicken litter its concrete understanding of the differences with biomass and effects of other gasifying parameters is still lacking and much desired.

Using steam as the gasifying agent is known to generate a higher quality syngas with high amounts of hydrogen content [32-34]. The high latent heat required for evaporation makes steam the most expensive gasifying agent and thus long reaction time is undesirable. On the other hand, air which is the cheapest agent generates the lowest quality syngas and fastest reaction rates. Using a mixture of air (oxygen) and steam as the gasifying agent provides the benefit of improved syngas quality while the exothermic reaction of air boosts the reaction rates. Steam can be injected at later stages in gasifiers [35], to reform the syngas and improve its quality or it can be mixed with air at early stages of the gasification [36], to give even improved concentrations of hydrogen. The concentration of oxygen in the gasifying agent plays an important role in the quality of 
syngas evolved and the rates of reaction. Thus the oxygen concentration needs to be optimized to seek for the most feasible reaction conditions [37].

The present paper investigates isothermal gasification of chicken manure at 1173 $\mathrm{K}$ using steam and low concentrations of oxygen. Nitrogen was used as a tracer calibration gas to determine the gas concentration of all the gases evolved during gasification. The evolved gases were analyzed using gas chromatography with specific focus on the temporal evolution of stable gas species yield and composition.

\section{Experimental}

\subsection{Reactor Facility}

A schematic diagram of the laboratory scale semi-batch reactor facility used for investigating the gasification behavior of chicken manure is given in Fig. 1. Nitrogen at known flow rate was used as a tracer gas for all the experiments that helped to quantify the amounts of various gas species evolved. Nitrogen mass flow rate was kept constant for all the conditions examined. High temperature steam at one atmosphere was generated using a hydrogen-oxygen flame. The hydrogen/oxygen ratio was adjusted by analyzing the flame product gases composition until no oxygen was present in the combustion products. For providing mixtures of steam-oxygen for gasification, oxygen flow rate was increased gradually until the desired ratio of steam and $\mathrm{O} 2$ in the products was obatined. The gas mixture after passing through the preheating electric tube furnace 
provided the desired temperature $(1173 \mathrm{~K})$ of the reactants. The chicken manure sample (35 g) was placed in a small quartz tube that was then inserted in to the test section of the main reactor (which was also electrically heated and set to the desired temperature within 5K) for conducting gasification studies under isothermal conditions. . When the temperature in both the furnaces reached the desired set point, the sample was then loaded through a quick disconnect coupling fitted to the second furnace (reactor). Time was counted starting from the time of sample insertion into the reactor.

Evolved gas mixture from the reactor was first condensed in an ice bath followed by a water bath to remove tar and moisture. The excess moisture in the sample was removed using anhydrous calcium chloride in a desiccant. A portion of the dry and tarfree syngas was transported to the gas chromatograph (GC) through sampling line while the remaining (excess) gases were vented out through the exhaust duct after dilution. The majority of the syngas yield was evolved during first 5 minutes so that the product gas mixture samples were collected in sampling bottles at each minute to determine the evolutionary behavior of syngas yield. This was due to the long sampling time required by the GC. After the first 5 minutes, sampling time was at longer time duration so that gas sample was directly introduced into the $\mathrm{GC}$ for the remaining duration of the reaction since the gas composition yield was much reduced and changes in gas composition were small. Micro GC was used to determine mole fractions of evolved gas species which allowed analysis of gas samples at a rate of approximately three minutes/sample during continuous acquisition. Micro GC was calibrated to quantify $\mathrm{H}_{2}, \mathrm{CO}, \mathrm{CO}_{2}, \mathrm{CH}_{4}, \mathrm{C}_{2} \mathrm{H}_{6}$, $\mathrm{C}_{2} \mathrm{H}_{4}, \mathrm{C}_{2} \mathrm{H}_{2}, \mathrm{~N}_{2}$ and $\mathrm{O}_{2}$ to an accuracy of $\pm 0.1 \%$. Note that the syngas refers to summation 
of $\mathrm{H}_{2}, \mathrm{CO}, \mathrm{CH}_{4}, \mathrm{C}_{2} \mathrm{H}_{4}, \mathrm{C}_{2} \mathrm{H}_{6}$, and $\mathrm{C}_{2} \mathrm{H}_{2}$ as these gases provided major contributors to heating value in the syngas evolved from gasification.

\subsection{Operating conditions}

Chicken manure used in the present investigation was a dried chicken manure fertilizer of irregular granular form, with sizes ranging from 1 to $3 \mathrm{~mm}$. The apparent density of particles measured from fluid immersion was $1.5 \mathrm{~g} \cdot \mathrm{ml}^{-1}$. These particles were filled in the quartz sample container with a packing density of $0.7 \mathrm{~g} . \mathrm{ml}^{-1}$. The ultimate and proximate analysis along with the lower heating value (LHV) [38] of the sample is given in Table 1. Nitrogen gas with a molar flow rate of 0.09 mol.min ${ }^{-1}$ was used for all the experiments reported here with reactor temperature maintained constant at $1173 \mathrm{~K}$. The estimated sample heating time was 1 min [39]. Hydrogen gas at a molar flow rate of 0.19 mol.min ${ }^{-1}$ was utilized in the burner while oxygen was adjusted according to the required concentration. Excess oxygen of 3\%,6\%, 9\%, and 12\% (excess refers to oxygen rich $\mathrm{H}_{2} / \mathrm{O}_{2}$ combustion) on the dry basis was tested which approximately corresponds to $1 \%, 2 \%, 3 \%$, and $4 \%$ of the total gasifying medium. Table 2 presents mole fraction of the gases at inlet to the reactor for the 5 different cases. The mole fraction of steam changed by only $2.5 \%$ from case 0 to case 12 , which makes the effects captured here mainly arising from change in the mole fraction of oxygen. The oxygen addition in the discussions here refers to excess oxygen added above the $\mathrm{H}_{2} \mathrm{O}$ and $\mathrm{N}_{2}$ content.

\section{Results and discussion}


The mole fraction data of dry and tar free product gases acquired from micro GC was post-processed to obtain mass flow rates of individual species. The mass flow rates were calculated using the known nitrogen flow rate and the standard density of gases as reported in the literature [40]. A parameter called energy yield was used for analyzing process output, which was computed as the aggregate of the cumulative mass yields over time of individual gas species multiplied by their corresponding heating values. Thus computed energy yield was compared with heat content in the sample mass according to its LHV to obtain energy conversion. Time integrals of mass flow rate of individual species and their carbon content was computed to compare the overall effect of oxygen addition on product gas output. The molar yields of gas species were processed to obtain mole fraction of major species in the cumulative yields.

\subsection{Evolution of Product gas flow-rate}

Figure 2 shows the evolution of hydrogen mass flow rate from gasification in steam at various oxygen concentrations in the gasifying medium. The peak value increased with increase in the percentage of oxygen until $6 \%$ then decreased at $9 \%$ and $12 \%$ oxygen concentration (based on dry basis). Also, the peak location as well as the total gasification time slightly shifted to earlier times, which indicate faster gasification reactions. The larger peaks and faster reactions can be due to the exothermic reaction of oxygen with the gases providing energy to promote the pyrolytic stage. The further decrease in the peak value for oxygen concentrations above $6 \%$ is attributed to burning of syngas due to the abundance of oxygen at a rate higher than the positive effect of added 
oxygen. In the case of $0 \%$ oxygen, the peak tends to be flatter, and the hydrogen production continued for a longer period. In general, the total hydrogen fuel gas produced decreased due to the oxidation, but the total reaction time was reduced by $50 \%$ when $3 \%$ of oxygen was added and by $70 \%$ when $12 \%$ of oxygen added. With the furnace maintained at $1173 \mathrm{~K}$, the overall process efficiency can be improved if some of the gases can be sacrificed to shorten the sample residence time in the reactor.

Unlike the hydrogen yield, the methane gas yield shown in Fig. 3 implies a definite improvement in the methane gas yield with the increase of oxygen concentration. This improvement is less significant compared to the overall decline in hydrogen yield because methane is only produced during the early stages of pyrolysis and for a short period compared to hydrogen. The absolute increase in methane gas yield can be attributed to the exothermic energy available from hydrogen combustion and the lower flammability limits of methane in the presence of such low oxygen concentrations. So, no further decrease in the peak value was observed for the range of oxygen concentrations examined. Another source of methane is from the cracking of tar due to the exothermic reactions that accompany in the presence of oxygen.

The carbon monoxide gas yield was significantly increased at up to $9 \%$ oxygen concentration in the gasification medium, after which the $\mathrm{CO}$ production decreased. Carbon monoxide is generated from breaking of the organic chains, dissociation of carbon dioxide (Eq. (2)), water gas shift reactions (Eq. (3) and (4)), and the incomplete combustion of fixed carbon. At the $1173 \mathrm{~K}$, Eq. (3) favors the formation of carbon monoxide. When the oxygen concentration was increased beyond 9\%, a complete 
combustion took place along with less dissociation in the presence of the extra oxygen. This behavior is evident from Fig. 4. The total reaction time was also decreased with increase in the oxygen concentration that also supported a comparable yield in hydrogen.

Carbon dioxide flow rate was of the same order as the syngas yield (compare Fig. 5 and Fig. 6). The main source of carbon dioxide is attributed to breaking of the carboxylic bonds in the organic manure chains and complete combustion of char and hydrocarbons. During the first 10 minutes, all the samples responded in a similar manner irrespective of the presence of excess oxygen or not, except for the $12 \%$ oxygen sample case, see Fig. 5. With $12 \%$ oxygen the peak value slightly increased compared to all other cases, but a significant increase was observed after the peak (at about 10 minutes into gasification), where the carbon dioxide flow rate was higher by some $40 \%$ compared to the $0 \%$ oxygen case. During the first 10 minutes, the major $\mathrm{CO}_{2}$ source was from pyrolysis with minor production from char combustion. Therefore, all the samples responded similarly. With complete pyrolysis, the effect of excess oxygen was more noticeable as the $\mathrm{CO}_{2}$ was mainly produced from the oxidation of char. Figures 2-5 show that the gasification reaction completed faster when oxygen was added to the samples.

Figure 6 shows the total syngas yield for the different cases. The total syngas yield accounts for only gases that provide a positive heating value and they included: $\mathrm{H}_{2}$, $\mathrm{CO}, \mathrm{CH}_{4}, \mathrm{C}_{2} \mathrm{H}_{6}, \mathrm{C}_{2} \mathrm{H}_{4}$, and $\mathrm{C}_{2} \mathrm{H}_{2}$. During the first 10 minutes, a significant improvement in the total flow rate of syngas was achieved by adding oxygen to the steam. After five minutes, the syngas yield declined and the $0 \%$ case continued to generate syngas till the $40^{\text {th }}$ minute while the process was complete in less than 25 minutes when the oxygen was 
added. Oxygen addition of 6,9 , and $12 \%$ had very similar behavior on the total syngas yield flow rate, but the gas composition was different as seen from Figs. 2-4. The total energy yield based on the gas composition is discussed in the next subsection.

The mole fraction of major gas species in accumulative product gas yield varied with oxygen concentration in the gasifying medium, see Fig. 7. Hydrogen content in the product gas yield decreased with the increase in $\mathrm{O}_{2}$ concentration attributing to increase in $\mathrm{CO}$ and $\mathrm{CO}_{2}$ mole fractions due to better oxidizing conditions. The variation of $\mathrm{CO}$ mole fraction showed a maximum for $9 \% \mathrm{O}_{2}$ content case showing the limitations of increasing the inlet $\mathrm{O}_{2}$ content. The output mole fraction variation by oxygen addition reveals potential benefits of $\mathrm{H}_{2}$ :CO ratio adjustments that can be optimized to provide product gas with ideal $\mathrm{H}_{2}: \mathrm{CO}$ ratio of 2 for reformation to liquid fuels. It is envisioned that this process may need further processing to remove $\mathrm{CO}_{2}$ and other hydrocarbons. The $\mathrm{CO}_{2}$ mole fraction decreased (compare case 0 to case 3 ), but then increased with oxygen content for the other cases. This decrease from case 0 to case 3 corresponds to improved partial oxidation of char to $\mathrm{CO}$, and thus $\mathrm{CO}$ occupies a larger volume and decreases the volume percentage occupied by $\mathrm{CO}_{2}$, see Eqn. (1-2). The excess oxygen reacted with char for partial oxidation. But with increase in oxygen content, the added oxygen also tends to further oxidize $\mathrm{CO}$, tar, and hydrocarbons to form $\mathrm{CO}_{2}$. This increase in $\mathrm{CO}_{2}$ over $\mathrm{CO}$ is observed by the decrease in $\mathrm{CO}$ content and increase in $\mathrm{CO}_{2}$ content between case 9 and 12 .

Figures 8-10 represent the evolution of mole fractions of major species in dry and tar-free product gas with time. During the initial 4 minutes of the reaction, $\mathrm{CO}_{2}$ mole fraction was dominant from decarboxylation reaction during pyrolysis phase. Progressive 
increase in time decreased $\mathrm{CO}_{2}$ mole fraction with increase in reforming and char gasification reactions given in Eq. (2\&4) from the char that was formed during pyrolysis. These gasification reactions form $\mathrm{H}_{2}$ and $\mathrm{CO}$ from slow heterogeneous reaction between char and $\mathrm{H}_{2} \mathrm{O}$ or $\mathrm{CO}_{2}$. Addition of $\mathrm{O}_{2}$ provided a readily available $\mathrm{O}$ to react with char to form $\mathrm{CO}$ leading to an increase in $\mathrm{CO}$ mole fraction. The trends on $\mathrm{H}_{2}$ and $\mathrm{CO}$ evolution were similar especially in Fig. 10 which shows a resemblance in $\mathrm{H}_{2}$ and $\mathrm{CO}$ evolution due to their similar chemical reaction source from heterogeneous char reaction. As the time proceeded, mass of leftover char reduced which made the net rate of $\mathrm{CO}$ production to be lower and also caused excess oxygen environment leading to $\mathrm{CO}$ oxidation and rise in $\mathrm{CO}_{2}$ mole fraction. The compositional differences cause different evolution trends in $\mathrm{CO}$ and $\mathrm{H}_{2}$ as seen in Fig. 8 when compared with steam gasification case [40].

\subsection{Cumulative energy yield}

The results shown in all the above figures showed that the conversion reaction was faster with oxygen addition to the steam. But in order to obtain quantitative assessment of the results, the total energy yield must be investigated. The total energy yield was calculated from the determined gas flow rates and heating values. Figure 11 shows the total energy yield along with the LHV of product gas for different concentrations of added oxygen. The total energy yield decreased with the increase in oxygen percentage added which was due to the combustion of some of the gases in the presence of an oxidizer and high temperatures. Even though Fig. 6 showed an increase in the total gas yield, the decrease in the total hydrogen yield shown in Fig. 2 lead to a reduction in the net energy yield. The increase in CO yields led to a peak in LHV of product gas for case 9, see Fig. 11. This enhances the chicken manure gasification 
product quality with minimal loss in energy output. The loss in energy output was apparent only for time integration for complete gasification. It can also be observed from Fig. 11 that even though case 0 produced highest total energy yield, case 9 produced the highest gas quality but at a reduced mass flow rate.

In order to assess the improvement in the reaction time, an accumulative energy yield was calculated for each case and the results are shown in Fig. 12. After 15 minutes from the start of the reaction, all the cases where oxygen was added had already generated more than $90 \%$ of the total gas yield, while the $0 \%$ case did not reach this percentage for 11 more minutes. For instance, after 10 minutes, different cases of $0 \%$, $3 \%, 6 \%, 9 \%$ and $12 \%$ oxygen addition had generated $144 \mathrm{~kJ}, 173 \mathrm{~kJ}, 203 \mathrm{~kJ}, 201 \mathrm{~kJ}$, and $193 \mathrm{~kJ}$ respectively. Thus, if the residence period was to be reduced to $10 \mathrm{~min}$, then adding up to $6 \%$ oxygen to the steam improved the energy yield by $62 \%$, even though the total energy yields for full conversion decreased by only $5 \%$ for the same case. At 10 min, from the start of gasification, all the cases with added oxygen had yielded more energy than the $0 \%$ oxygen case.

The fractional changes in the carbon conversion and energy conversion $\left(\frac{\text { product gas } * L H V_{\text {gas }}}{\text { feedstock mass } * L H V}\right)$ were computed and the results obtained are reported in Fig. 13 . These results justify the advantage obtained by oxygen addition with up to $50 \%$ increase in carbon conversion compared to the case with no excess oxygen (case 0). The loss in energy conversion due to excess oxygen was less than $10 \%$ for case 0 with the loss increased with oxygen content in gasifying medium. Such a huge gain in conversion 
efficiency with minimal loss in energy output makes this an favorable pathway for improving the gasification efficiency of low-grade feedstock materials.

\subsection{Residual mass and tar}

The evaluation of tar for this set up was not practical as significant mass of tar precipitated on the walls of the pipes before condensation and other mass of tar was carried by the gas after condensation. Any calculation of the tar mass using the condensate would not have been accurate. Instead, we focused on change in net carbon conversion denoting solid to product gas conversion as a reliable parameter along with product gas low heating value (LHV). The objective of oxygen addition was to improve carbon conversion with limited amounts of oxygen addition that would negatively impact the product gas LHV or energy conversion due to dilution from increased $\mathrm{CO}_{2}$ concentration, see Fig. 13.

The mass of ash was found consistent for all of the cases and it varied between $19 \%-20 \%$ of the initial mass with no clear dependence on the excess oxygen concentration. This was to be expected from complete gasification of the material. The ability of material destruction and ash recovery makes gasification a useful technique for waste disposal. The high ash content in chicken manure although makes the feedstock of lower energy density than coal or conventional biomass. However, addition of oxygen can boost the performance of chicken manure gasification by lowering net energy input and process time with minimal changes in output syngas yields. 


\subsection{Error Analysis}

The accuracy of the calibrated gas compositions from the micro GC was estimated to be $0.1 \%$. The inlet mass flow rates and temperature were calibrated to $2 \%$ accuracy. Case 0 was run three times and the standard deviation of product gas mole fractions was within $5 \%$ of the results. Since there was no change in the experimental setup the results from other cases were assumed to be within the measured error for case 0 .

\section{Conclusions}

Enhancement gasification reaction rates with the addition of small amounts of oxygen to steam gasification for chicken litter waste were carried out at $1173 \mathrm{~K}$ in semibatch isothermal reactor. Adding oxygen to steam gasification significantly decreased the total reaction time by some $50 \%$. At $12 \%$ oxygen addition the reaction time decreased by 70\%. The total energy yield was decreased by $4 \%-15 \%$ depending on the oxygen (percent) added. An accumulative time analysis performed on the results revealed improved accumulative yield for up to 20 minutes for all cases reported here. Addition of oxygen was found to be favorable economic option to significantly shorten the waste

manure residence time which enabled lesser process energy requirement to generate steam required for gasification.

\section{Acknowledgments}


The support from the Office of Naval Research (ONR) in this research is gratefully acknowledged.

\section{References}

[1] National Chicken Council n.d. http://www.nationalchickencouncil.org/about-theindustry/statistics/per-capita-consumption-of-poultry-and-livestock-1965-to-estimated-2012-inpounds/ (accessed July 1, 2016).

[2] The Agriculture Phosphorus Initiatve 2016. http://mda.maryland.gov/Pages/PMT.aspx (accessed July 1, 2016).

[3] Kelleher B., Leahy J., Henihan A., O’Dwyer T., Sutton D, Leahy M. Advances in poultry litter disposal technology - a review. Bioresour Technol 2002;83:27-36. doi:10.1016/S09608524(01)00133-X.

[4] Kumar A, Jones DD, Hanna MA. Thermochemical Biomass Gasification: A Review of the Current Status of the Technology. Energies 2009;2:556-81. doi:10.3390/en20300556.

[5] Bahng M-K, Mukarakate C, Robichaud DJ, Nimlos MR. Current technologies for analysis of biomass thermochemical processing: a review. Anal Chim Acta 2009;651:117-38. doi:10.1016/j.aca.2009.08.016.

[6] Kalinci Y, Hepbasli A, Dincer I. Biomass-based hydrogen production: A review and analysis. Int J Hydrogen Energy 2009;34:8799-817. doi:10.1016/j.ijhydene.2009.08.078.

[7] Woolcock PJ, Brown RC. A review of cleaning technologies for biomass-derived syngas. Biomass and Bioenergy 2013;52:54-84. doi:10.1016/j.biombioe.2013.02.036. 
[8] Sutton D, Kelleher B, Ross JRH. Review of literature on catalysts for biomass gasification. Fuel Process Technol 2001;73:155-73. doi:10.1016/S0378-3820(01)00208-9.

[9] Bulushev DA, Ross JRH. Catalysis for conversion of biomass to fuels via pyrolysis and gasification: A review. Catal Today 2011;171:1-13. doi:10.1016/j.cattod.2011.02.005.

[10] Tanksale A, Beltramini JN, Lu GM. A review of catalytic hydrogen production processes from biomass. Renew Sustain Energy Rev 2010;14:166-82. doi:10.1016/j.rser.2009.08.010.

[11] Saxena RC, Seal D, Kumar S, Goyal HB. Thermo-chemical routes for hydrogen rich gas from biomass: A review. Renew Sustain Energy Rev 2008;12:1909-27. doi:10.1016/j.rser.2007.03.005.

[12] Puig-Arnavat M, Bruno JC, Coronas A. Review and analysis of biomass gasification models. Renew Sustain Energy Rev 2010;14:2841-51. doi:10.1016/j.rser.2010.07.030.

[13] Chhiti Y, Kemiha M. Thermal Conversion of Biomass, Pyrolysis and Gasification : A Review. Int J Eng Siences 2013;2:75-85.

[14] Pereira EG, da Silva JN, de Oliveira JL, Machado CS. Sustainable energy: A review of gasification technologies. Renew Sustain Energy Rev 2012;16:4753-62. doi:10.1016/j.rser.2012.04.023.

[15] Parthasarathy P, Narayanan KS. Hydrogen production from steam gasification of biomass: Influence of process parameters on hydrogen yield - A review. Renew Energy 2014;66:570-9. doi:10.1016/j.renene.2013.12.025.

[16] Mohan D, Pittman CU, Steele PH. Pyrolysis of Wood / Biomass for Bio-oil : A Critical Review. Energy \& Fuesl 2006;20:848-89. doi:10.1021/ef0502397.

[17] McKendry P. Energy production from biomass (part 1): overview of biomass. Bioresour 
Technol 2002;83:37-46. doi:10.1016/S0960-8524(01)00118-3.

[18] Wang L, Weller CL, Jones DD, Hanna MA. Contemporary issues in thermal gasification of biomass and its application to electricity and fuel production. Biomass and Bioenergy 2008;32:573-81. doi:10.1016/j.biombioe.2007.12.007.

[19] Kamińska-Pietrzak N, Smoliński A. Selected Environmental Aspects of Gasification and Co-Gasification of Various Types of Waste. J Sustain Min 2013;12:6-13. doi:10.7424/jsm130402.

[20] Higman C, van der Burgt M, Higman C, van der Burgt M. Chapter 1 - Introduction. Gasification, 2008, p. 1-9. doi:10.1016/B978-0-7506-8528-3.00001-8.

[21] Kim S-S, Agblevor FA. Pyrolysis characteristics and kinetics of chicken litter. Waste Manag 2007;27:135-40. doi:10.1016/j.wasman.2006.01.012.

[22] DEJONG W, DINOLA G, VENNEKER B, SPLIETHOFF H, WOJTOWICZ M. TGFTIR pyrolysis of coal and secondary biomass fuels: Determination of pyrolysis kinetic parameters for main species and NOx precursors. Fuel 2007;86:2367-76. doi:10.1016/j.fuel.2007.01.032.

[23] Kim S-S, Agblevor FA, Lim J. Fast pyrolysis of chicken litter and turkey litter in a fluidized bed reactor. J Ind Eng Chem 2009;15:247-52. doi:10.1016/j.jiec.2008.10.004.

[24] Agblevor FA, Beis S, Kim SS, Tarrant R, Mante NO. Biocrude oils from the fast pyrolysis of poultry litter and hardwood. Waste Manag 2010;30:298-307. doi:10.1016/j.wasman.2009.09.042.

[25] Joseph P, Tretsiakova-McNally S, McKenna S. Characterization of cellulosic wastes and gasification products from chicken farms. Waste Manag 2012;32:701-9. 
doi:10.1016/j.wasman.2011.09.024.

[26] Font-Palma C. Characterisation, kinetics and modelling of gasification of poultry manure and litter: An overview. Energy Convers Manag 2012;53:92-8. doi:10.1016/j.enconman.2011.08.017.

[27] Priyadarsan S, Annamalai K, Sweeten JM, Holtzapple MT, Mukhtar S. Co-gasification of blended coal with feedlot and chicken litter biomass. Proc Combust Inst 2005;30:2973-80. doi:10.1016/j.proci.2004.08.137.

[28] Kirubakaran V, Sivaramakrishnan V, Premalatha M, Subramanian P. Kinetics of AutoGasification of Poultry Litter. Int J Green Energy 2007;4:519-34. doi:10.1080/15435070701583102.

[29] Xiao X, Le DD, Li L, Meng X, Cao J, Morishita K, et al. Catalytic steam gasification of biomass in fluidized bed at low temperature: Conversion from livestock manure compost to hydrogen-rich syngas. Biomass and Bioenergy 2010;34:1505-12. doi:10.1016/j.biombioe.2010.05.001.

[30] Yanagida T, Minowa T, Nakamura A, Matsumura Y, Noda Y. Behavior of inorganic elements in poultry manure during supercritical water gasification. Nihon Enerugi Gakkaishi/Journal Japan Inst Energy 2008. doi:10.3775/jie.87.731.

[31] Yanagida T, Minowa T, Shimizu Y, Matsumura Y, Noda Y. Recovery of activated carbon catalyst, calcium, nitrogen and phosphate from effluent following supercritical water gasification of poultry manure. Bioresour Technol 2009;100:4884-6. doi:10.1016/j.biortech.2009.05.042.

[32] Pinto F, André R, Miranda M, Neves D, Varela F, Santos J. Effect of gasification agent on co-gasification of rice production wastes mixtures. Fuel 2016;180:407-16. 
doi:10.1016/j.fuel.2016.04.048.

[33] Mahinpey N, Gomez A. Review of gasification fundamentals and new findings: Reactors, feedstock, and kinetic studies. Chem Eng Sci 2016;148:14-31. doi:10.1016/j.ces.2016.03.037.

[34] Karatas H, Olgun H, Akgun F. Experimental results of gasification of waste tire with air\&amp;CO2, air\&amp;steam and steam in a bubbling fluidized bed gasifier. Fuel Process Technol 2012;102:166-74. doi:10.1016/j.fuproc.2012.04.013.

[35] Sharma S, Sheth PN. Air-steam biomass gasification: Experiments, modeling and simulation. Energy Convers Manag 2016;110:307-18. doi:10.1016/j.enconman.2015.12.030.

[36] Broer KM, Woolcock PJ, Johnston PA, Brown RC. Steam/oxygen gasification system for the production of clean syngas from switchgrass. Fuel 2015;140:282-92. doi:10.1016/j.fuel.2014.09.078.

[37] Arabloo M, Bahadori A, Ghiasi MM, Lee M, Abbas A, Zendehboudi S. A novel modeling approach to optimize oxygen-steam ratios in coal gasification process. Fuel 2015;153:1-5. doi:10.1016/j.fuel.2015.02.083.

[38] Phyllis2, database for biomass and waste 2015; https://www.ecn.nl/phyllis2; Energy research Centre of the Netherlands

[39] Ahmed II, Gupta AK. Sugarcane bagasse gasification: Global reaction mechanism of syngas evolution. Appl Energy 2012;91:75-81. doi:10.1016/j.apenergy.2011.07.001.

[40] Ahmed I, Gupta AK. Syngas yield during pyrolysis and steam gasification of paper. Appl Energy 2009;86:1813-21. doi:10.1016/j.apenergy.2009.01.025. 


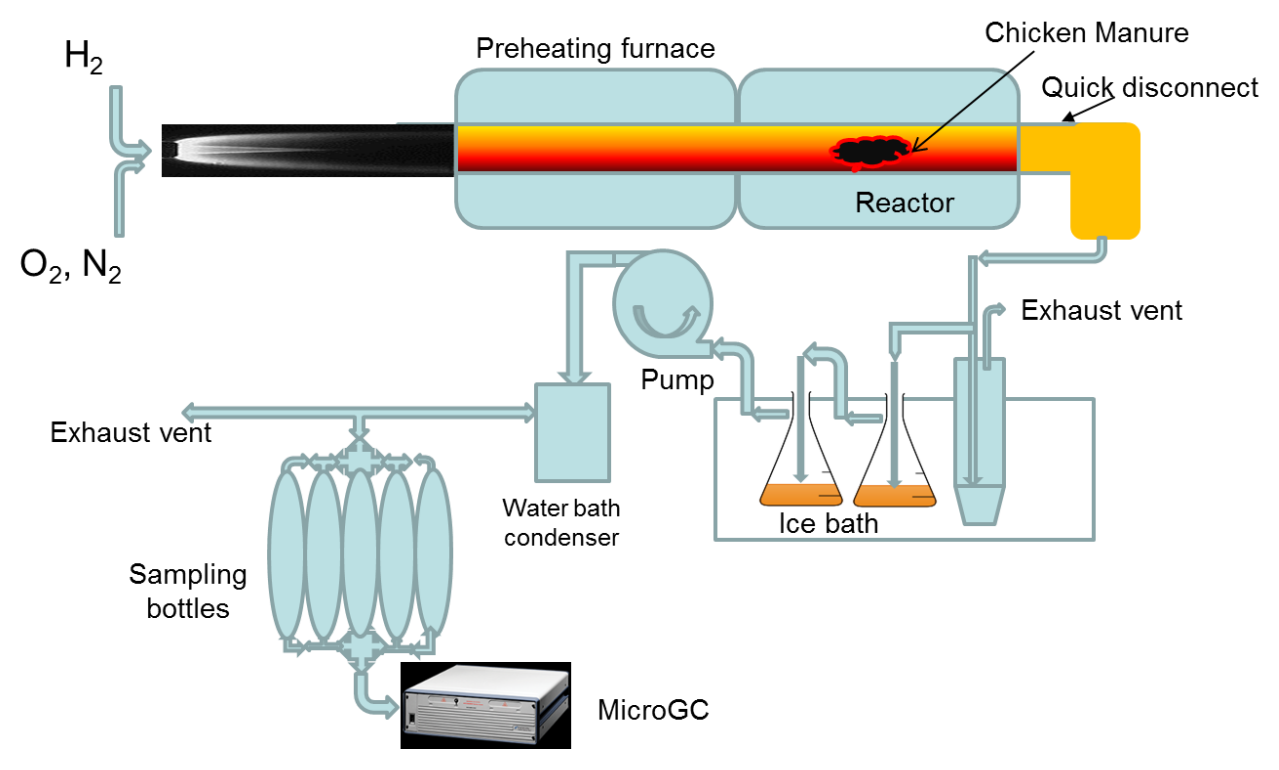

Figure 1. A schematic diagram of the experimental setup 


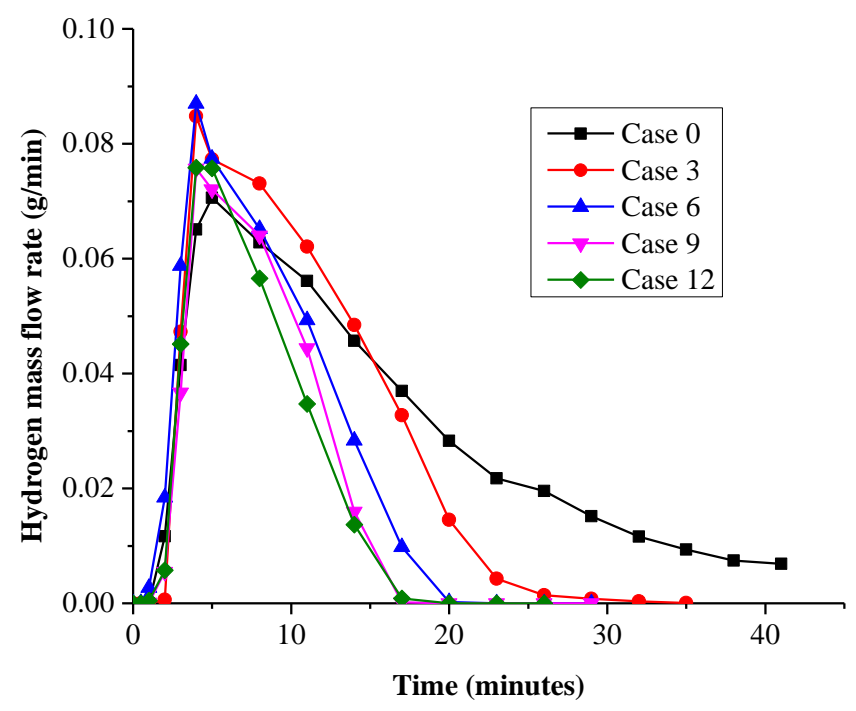

Figure 2. Evolutionary behavior of hydrogen mass flow rate for different oxygen concentrations in the gasifying medium 


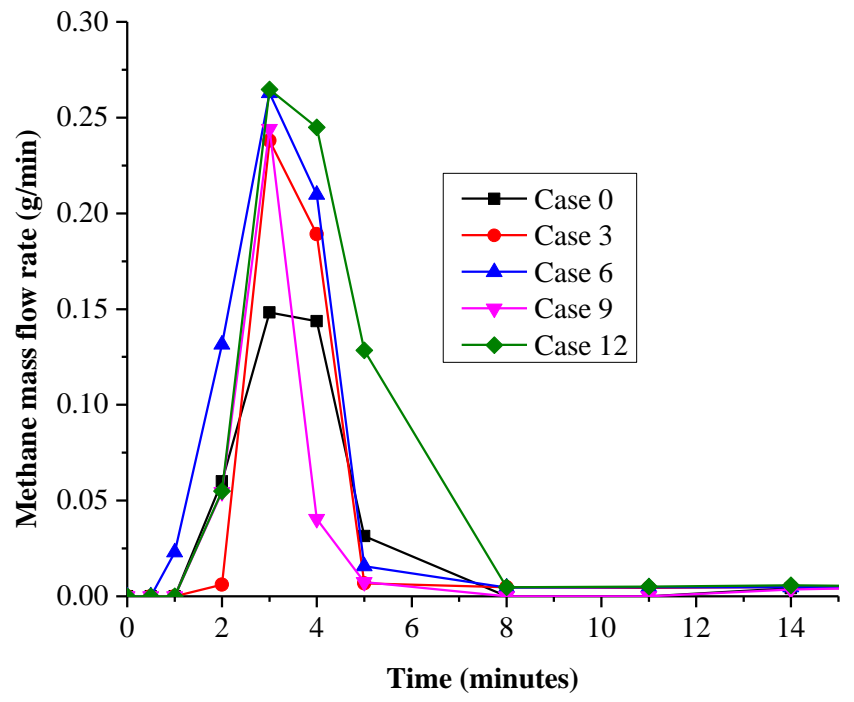

Figure 3. Evolutionary behavior of methane mass flow rate for different oxygen concentrations in the gasifying medium 


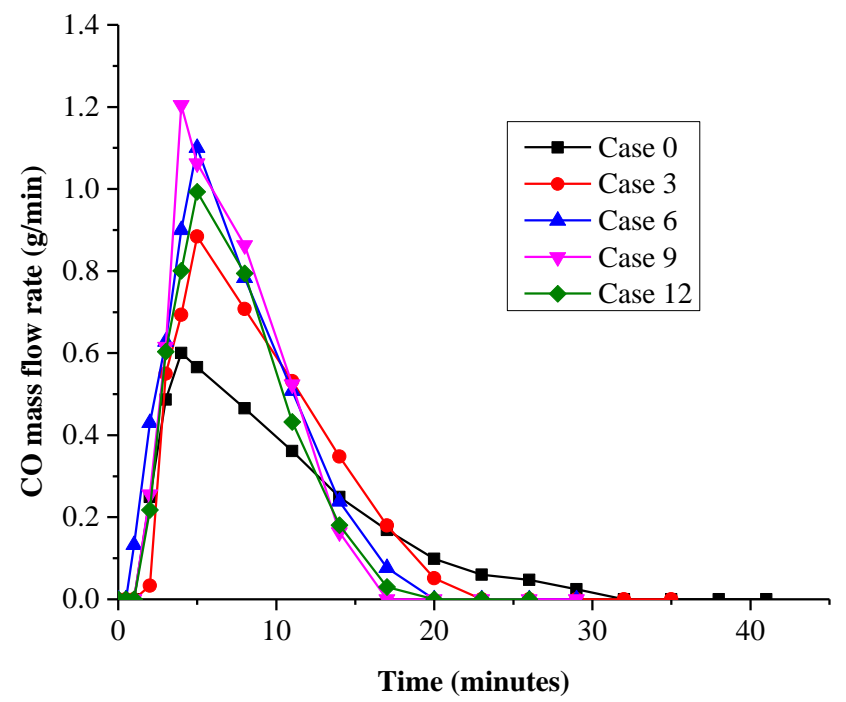

Figure 4. Evolutionary behavior of carbon monoxide mass flow rate for different oxygen concentrations in the gasifying medium. 


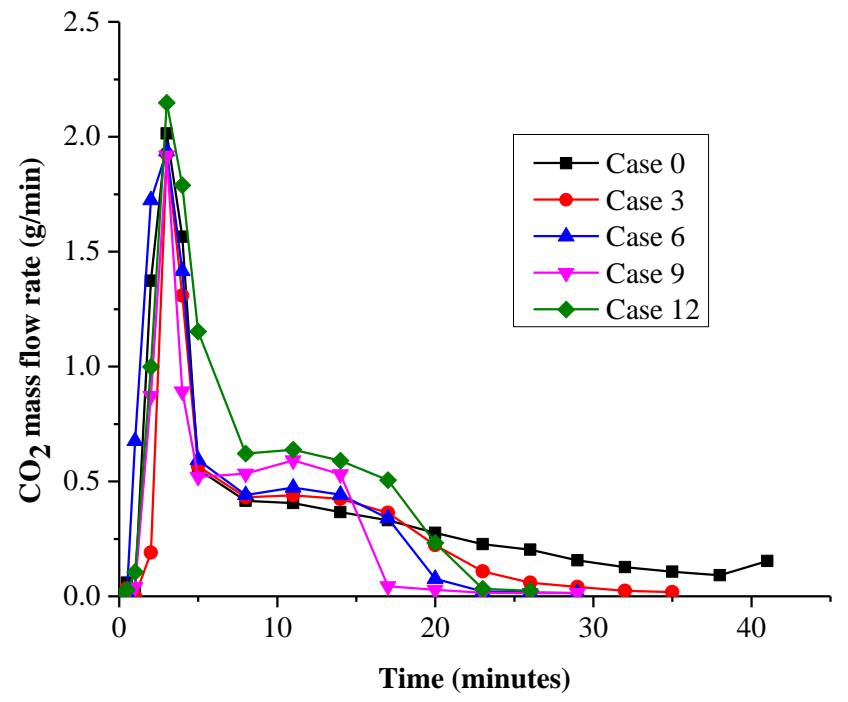

Figure 5. Evolutionary behavior of carbon dioxide mass flow rate for different oxygen concentrations in the gasifying medium. 


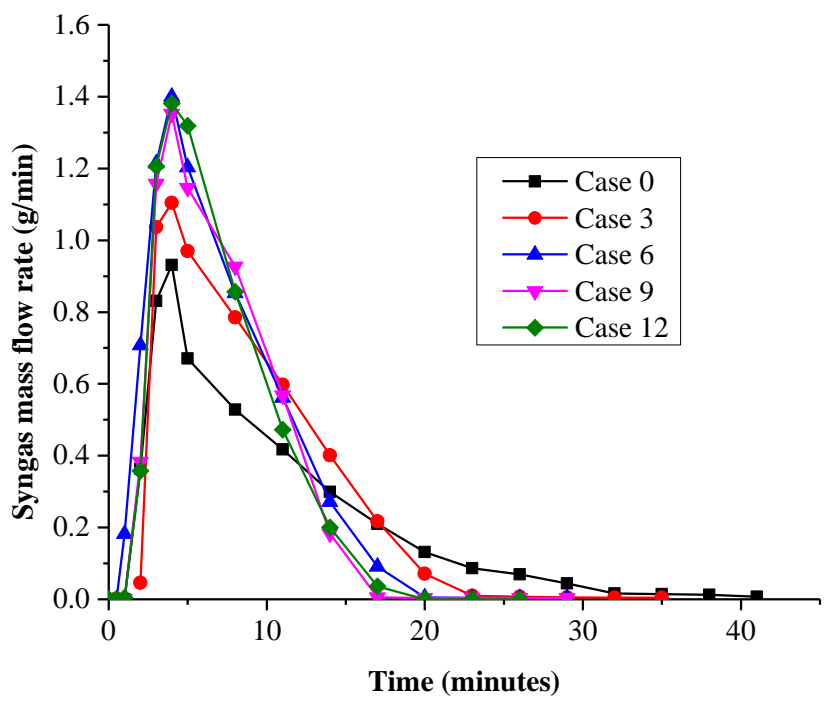

Figure 6. Evolutionary behavior of total syngas mass flow rate with different oxygen concentrations in the gasifying medium. 


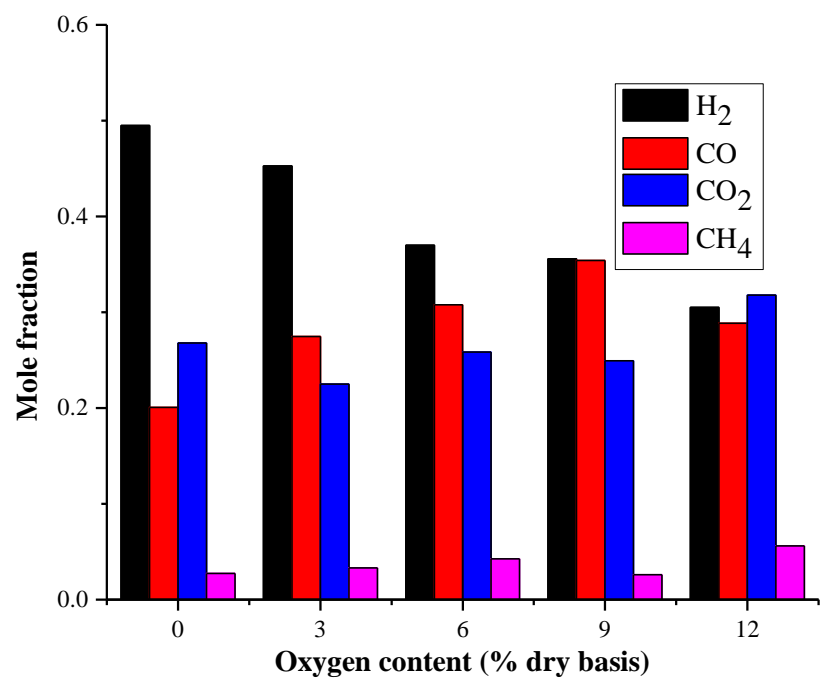

Figure 7. Mole fraction of major species in accumulative syngas yield for different oxygen concentrations in the gasifying medium 


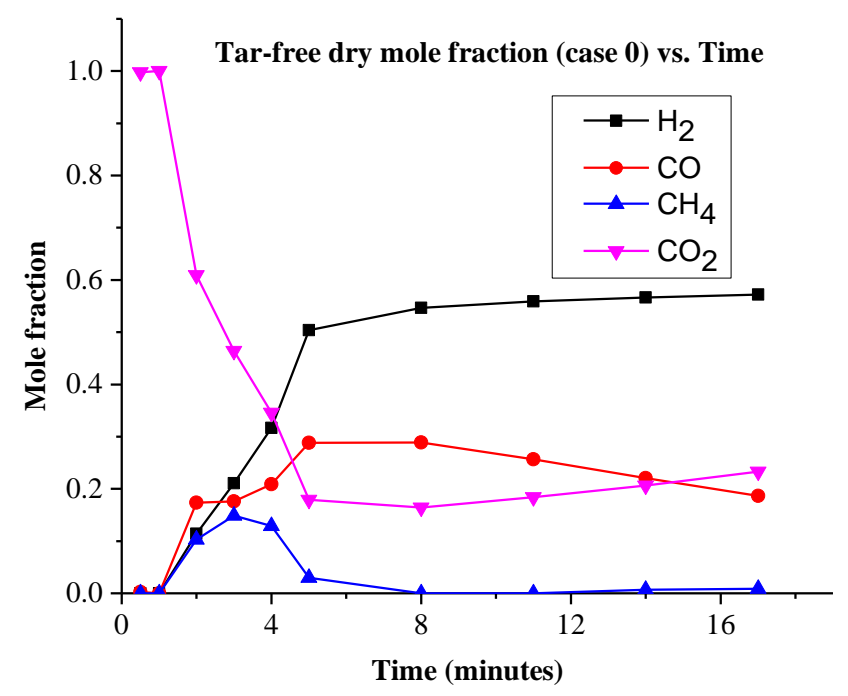

Figure 8. Temporal evolution of mole fraction of major species in tar-free dry syngas (case 0 ) 


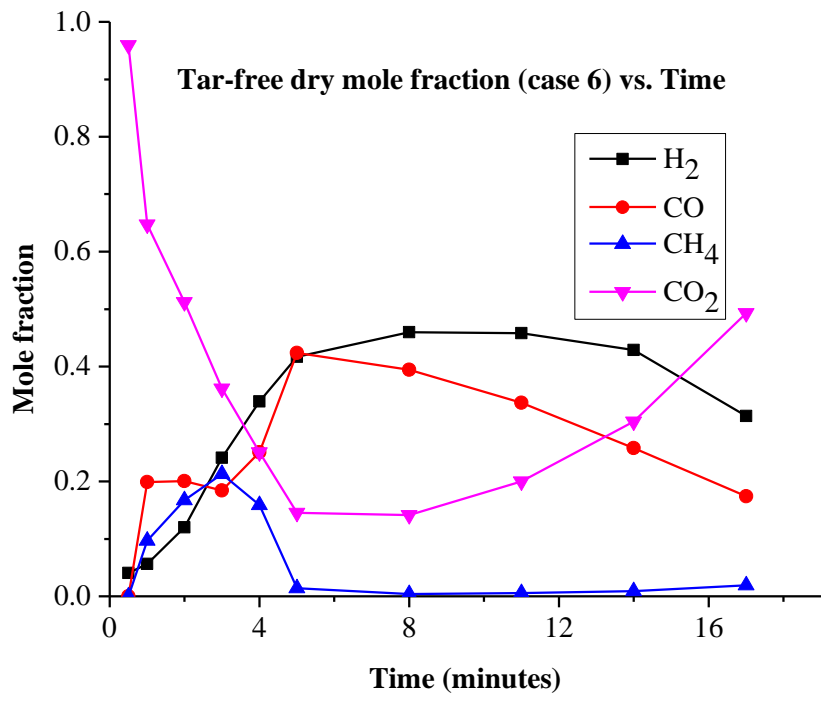

Figure 9. Temporal evolution of mole fraction of major species in tar-free dry syngas (case 6) 


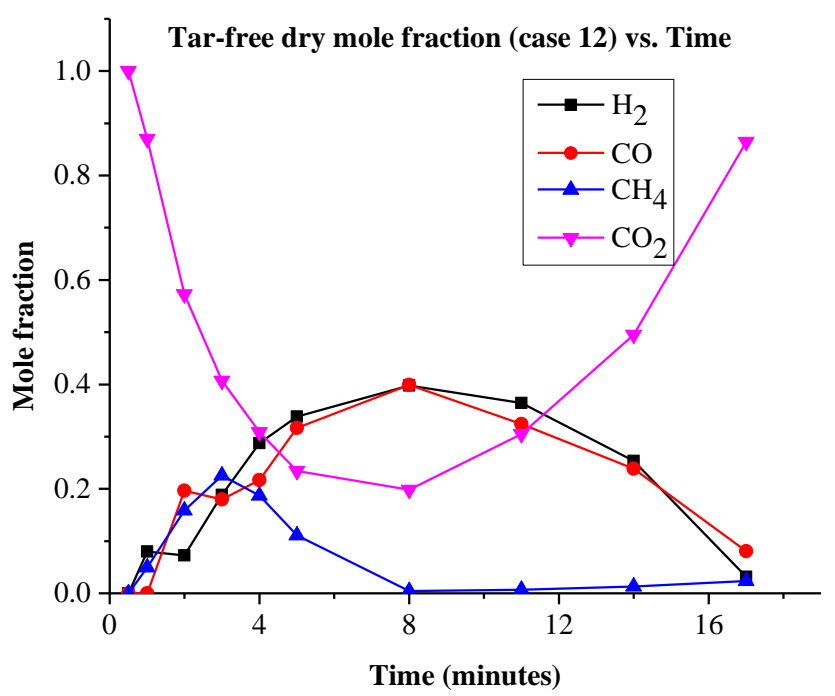

Figure 10. Temporal evolution of mole fraction of major species in tar-free dry syngas (case 12) 


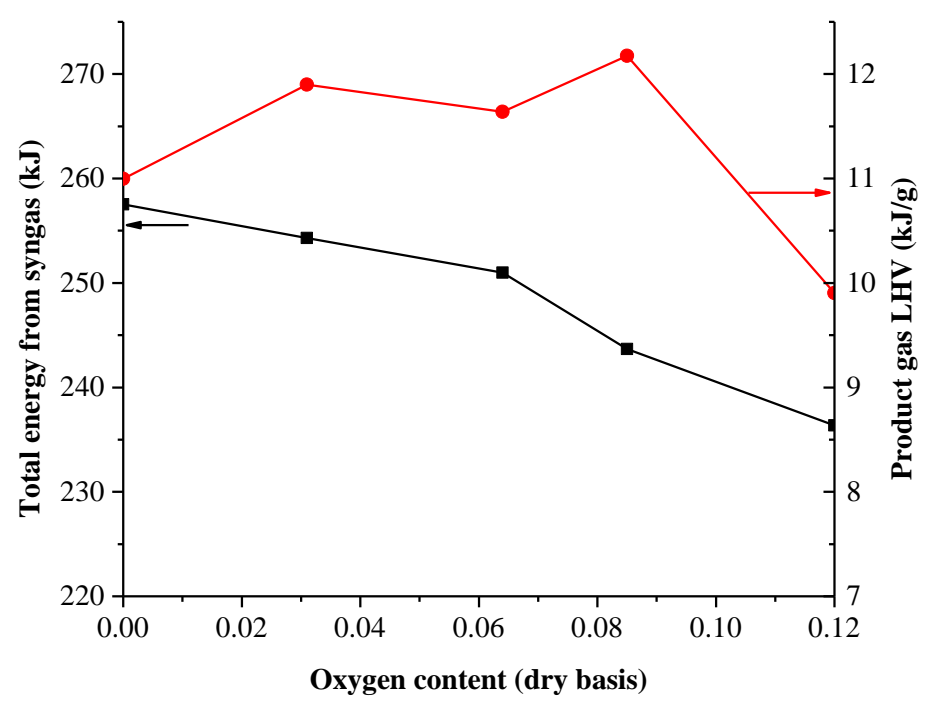

Figure 11. Total energy yield and product gas LHV for different oxygen concentrations in the gasifying medium. 


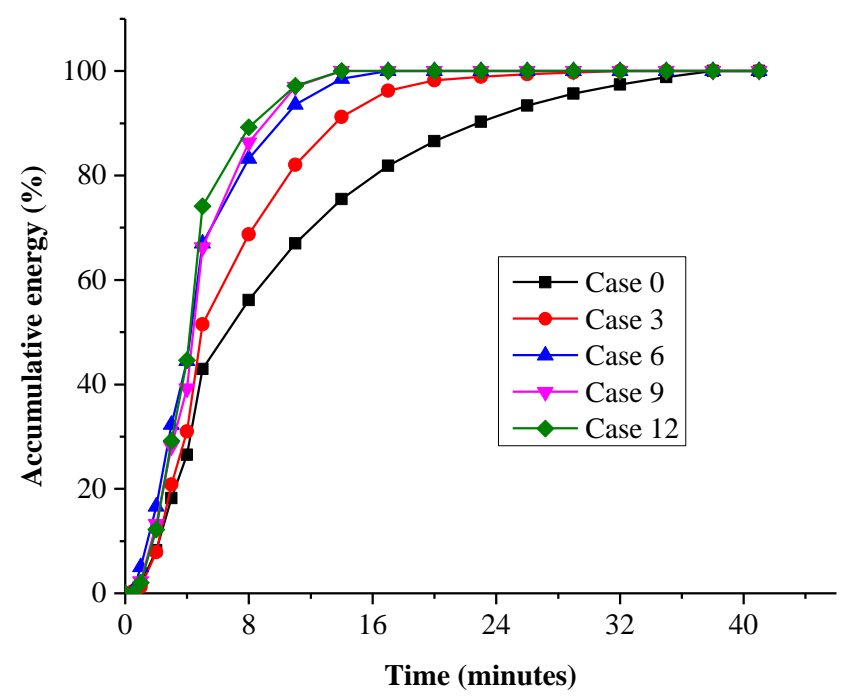

Figure 12. Accumulative energy yield evolution for different oxygen concentrations in the gasifying medium. 


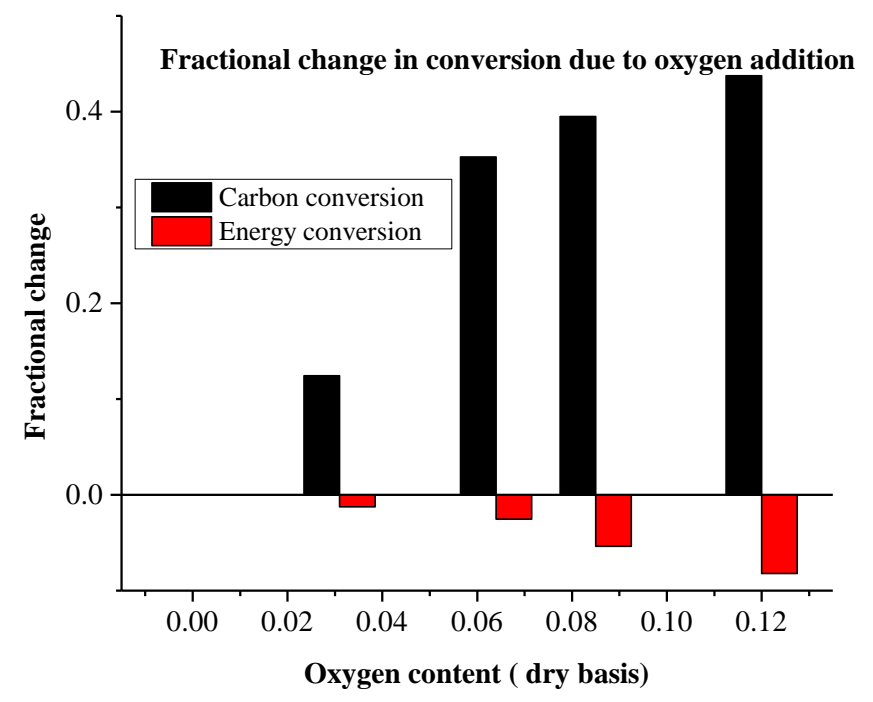

Figure 13. Fractional change in carbon and energy conversion with respect case 0 for different oxygen concentrations in the gasifying medium. 
Table 1. Proximate and ultimate analysis of chicken manure [38]

\begin{tabular}{|l|l|}
\hline Proximate Analysis (wt. \% dry) & \\
\hline Volatile content & 65.56 \\
\hline Ash content at $550^{\circ} \mathrm{C}$ & 21.65 \\
\hline Fixed carbon & 12.8 \\
\hline Ultimate Analysis (wt. \% dry) & \\
\hline Carbon & 35.59 \\
\hline Hydrogen & 4.57 \\
\hline Nitrogen & 4.98 \\
\hline Sulfur & 1.45 \\
\hline Oxygen & 35.52 \\
\hline HHV (in MJ/kg) & 13.15 \\
\hline
\end{tabular}


Table 2: The mole fraction of $\mathrm{N}_{2}$, steam, and $\mathrm{O}_{2}$ for the different cases.

\begin{tabular}{|l|l|l|l|}
\hline Case & $\mathrm{N}_{2}, \%$ & $\mathrm{H}_{2} \mathrm{O}, \%$ & $\mathrm{O}_{2}, \%$ \\
\hline 0 & 33.3 & 66.73 & 0 \\
\hline 3 & 33 & 66 & 1 \\
\hline 6 & 32.6 & 65.4 & 2 \\
\hline 9 & 32 & 65 & 3 \\
\hline 12 & 31.8 & 64.2 & 4 \\
\hline
\end{tabular}

